\title{
A Cross Sectional Study to Assess the Levels of Depression and Anxiety in Patients with Chronic Obstruction Pulmonary Disease in a Tertiary Care Hospital
}

\author{
Richa Sinha1 ${ }^{1}$, Trisha Gupta², Sonam Maheshwari ${ }^{3}$
}

${ }^{1}$ Assistant Professor, Department of Community Medicine, Government Doon Medical College, Dehradun, India; ${ }^{2}$ MBBS Student, Government Doon Medical College, Dehradun; ${ }^{3}$ Assistant Professor, Department of Community Medicine, Government Doon Medical College, Dehradun, India

\begin{tabular}{|c|c|c|c|c|c|c|c|c|}
\hline Abstract & Introduction & Methodology & Results & Conclusion & References & Citation & \multicolumn{2}{|c|}{ Tables / Figures } \\
\hline \multicolumn{9}{|c|}{ Corresponding Author } \\
\hline \multicolumn{8}{|c|}{$\begin{array}{l}\text { Dr. Sonam Maheshwari, Assistant Professor, Department of Community Medicine, Government } \\
\text { Doon Medical College, Dehradun, India-2448011 } \\
\text { E Mail ID: } \underline{\text { maheshwarisonam2@gmail.com }}\end{array}$} & 回和回 \\
\hline
\end{tabular}

\section{Citation}

Sinha R, Gupta T, Maheshwari S. A Cross Sectional Study to Assess the Levels of Depression and Anxiety in Patients with Chronic Obstruction Pulmonary Disease in a Tertiary Care Hospital. Indian J Comm Health. 2021;33(1):90-96. https://doi.org/10.47203/IJCH.2021.v33i01.012

Source of Funding: Nil Conflict of Interest: None declared

\section{Article Cycle}

Received: 04/01/2021; Revision: 17/02/2021; Accepted:14/03/2021; Published:31/03/2021

This work is licensed under a Creative Commons Attribution 4.0 International License.

\section{Abstract}

Objective: In the present study, demographic profile, knowledge and motivation of COPD patients attending tertiary hospital, the level of anxiety and depression is assessed. Materials and Methods: This cross-sectional study was carried out on consecutive patients with COPD during their routine out- and in-patient visits in the tertiary care hospital during 4 months (April 2019 to July 2019). Physician confirmed cases of more than 1-year duration were included in the study. Thus 194 COPD patients were admitted in the ward. They were interviewed by using HADS scale and Modified Morisky scale. The diagnosis of COPD was confirmed by Chest X- ray and Spirometery test and a history of exacerbation or hospitalization over past 6 months was also obtained. The chi square-test, t-test and one-way analysis of variance were used in the univariate analyses, whilst regression was used in the multiple variable analyses. Results: A total of 194 COPD individuals, 124 Males and 70 Females were enrolled in the study. The mean age of the respondents was $49.16 \pm 8.20$ (25-62) years. The mean scores for anxiety and depression were $19.12 \pm 2.38$ and $11.54 \pm 2.50$ respectively. Both anxiety and depression scores were statistically significant between the gender. Among males $70 \%$ cases were having no comorbid conditions; however, $57.10 \%$ females were having more than two comorbid conditions. Conclusion: Present study illustrates that anxiety and depression are common in patients with COPD, furthermore, patients with depressive disorders have more comorbidities in comparison with patient with anxiety.

\section{Keywords}

Depression; COPD Patients; Anxiety

\section{Introduction}

Chronic obstructive pulmonary disease (COPD) is a leading respiratory disease affecting globally with great potential of affecting the quality of life. The World Health Organization defines it as a lung disease characterized by chronic obstruction of lung airflow that interferes with normal breathing and is not fully reversible.(1) According to GOLD guidelines it is a progressive and partially reversible obstruction of air flow related to lungs' abnormal inflammatory 
response to gasses and different poisonous particles.(2)

It is a preventable and treatable illness and is one of the leading non-communicable causes of death globally, as well as in India. $(3,4,5)$ Globally 210 million people are affected and kills $>4$ million people every year, accounting for around $9 \%$ of total deaths. Usually low- and middle-income countries are affected accounting for ninety percent of these deaths. According to the World Health Organization report, the prevalence of COPD ranges between $4 \%$ and $20 \%$ in the Indian adults. It is predicted to become the third leading cause of death by 2030. $(6,7,8)$

COPD is a major cause of chronic morbidity; it was ranked 11th in 2002 and is projected to rise to seventh place in 2030.(9) Chronic obstructive pulmonary disease (COPD) is associated with impaired daily activities, reduced HRQoL, severe dyspnoea, and psychological burden of clinically relevant anxiety or depression.(10)

Patients of COPD are at a considerable risk of suffering from symptoms of depression and anxiety. $(11,12)$ The prevalence of anxiety symptoms varied from 30 to $90 \%$, and that of depressive symptoms ranged from 13 to $70 \%$ among COPD patients.(13-19) It is well documented that patient of COPD experiences significantly more psychological distress than the general population and significantly less than psychiatric outpatients.(20) To maximize QoL in patients with COPD, psychological factors need to be carefully assessed and addressed.(21) The association between depression and COPD appears to be bidirectional, as shown in a recent meta-analysis of longitudinal studies which demonstrated that not only COPD increases the risk of developing depression (relative risk 1.69; $95 \% \mathrm{Cl}$ 1.45-1.96) but also, depression increases 1.43 (95\% Cl 1.20-1.71) the risk of COPD adverse outcomes and mortality.(22) Although depression and anxiety are significant co-morbid condition in chronic illnesses, little is known about its level in patients with chronic obstructive pulmonary disease (COPD) in India.

\section{Aims \& Objectives}

1. To assess the demographic profile, knowledge and motivation of COPD patients attending tertiary hospital.

2. To assess the level of anxiety and depression among COPD patients.
Material \& Methods

Study type: Cross sectional study

Study population \& Study area: This cross-sectional study was carried out on consecutive patients with COPD during their routine out- and in-patient visits in our tertiary care hospital.

Study duration: The study was carried out for four months (April 2019 to July 2019).

Methodology: In order to be included in the study, the patient had to present with physician confirmed diagnosis of COPD > 1 year (by using the GOLD guideline with post bronchodilator FEV1/FVC $<70$ ). The patient should be less than 60 years and was on medication for depression and anxiety both. Two hundred and sixteen patients attending our respiratory unit were screened; twenty-two met with exclusion criteria and remaining 194 were enrolled. The levels of anxiety, depression, dyspnoea and treatment adherence were assessed in all cases using a self-administered semi structured questionnaire (in Hindi). We used Hospital Anxiety and Depression scale (HADS) to assess anxiety and depression, which contain 14 items in two subscales: anxiety (HADS-A) and depression (HADS-D), each with seven items (23). Approval from the Institutional Ethical committee was taken and written informed consent was obtained from the patients.

\section{Variables in the study are as follows:}

1. Severity of Dyspnoea -The modified medical resource council (MMRC) dyspnea scale was used. It consisted of five statements about perceived breathlessness: from grade 1 (I only get breathlessness with strenuous exercise) up to grade 5 (I'm too breathless to leave the house) (24).

2. Patient adherence can be defined as the extent to which a patient's behavior coincides with health-related advice, the ability to attend scheduled clinical appointments, make optimal life style changes, undergo recommended investigations and take medications as prescribed. Modified Morisky's Scale 6 item questionnaire is used to assess the adherence to the medications prescribed for COPD (25).

3. Number of comorbidities (diagnosed by a physician).

Data analysis: Data was entered in MS Excel; Data coding and analysis was conducted using Statistical Package for Social Sciences (SPSS) version 22. 
Demographics and clinical characteristics were compared among the groups using cross tabulation and chi square tests or Fisher exact test. Student $t$ test, Analysis of variance, Kruskal-Wallis and Wilcoxon tests are applied, depending on the normality of the data. Logistic regression was used to explore the severity of anxiety and depression. Age at marriage, gender, education level, occupation type, comorbidities, addiction, duration of disease, patient adherence, were considered as independent variable. Severity of Dyspnoea, BMI. P value of $<0.05$ was considered as statistical significance

\section{Results}

Total numbers of respondents were 194 (Male/ female: $124 / 70)$. The overall mean \pm SD age of all patients was $49.17 \pm 8.29(25-62)$ in years. Most of them were skilled by occupation (79.4) and married (85.6). In terms of educational status, only $16.5 \%$ were educated up to intermediate. The majority of male respondents had history of alcohol and smoking consumption, i.e., $77.2 \%$ and $58.2 \%$ respectively. It was observed that 113 (58.2\%) respondents had no associated comorbidities. The severity of dyspnoea was almost equal in male and female and found not to be significant, though the average score of anxiety and depression was statistically different in both the groups $(p<0.05)$. Significant difference was observed between disease duration and gender $(p=0.031)$. More than half of the patients had high knowledge and motivation regarding treatment adherence for COPD, also knowledge was significantly associated with gender. The mean scores for anxiety and depression were $19.77 \pm 2.15$ and $19.13 \pm 2.39$ respectively. Both anxiety and depression scores were statistically significant between the gender. Female with COPD were severely anxious and depressed and it was found to be significant. Number of comorbidities and history of alcohol consumption were also found to be statistically significant $(p<0.05)$.

(Table 1) reveals the characteristics of anxiety and depression of the study population. Gender, Educational status and BMI were significantly correlated with levels of anxiety and depression both. However, the age, marital status, number of comorbidities, alcohol use and motivation were statistically significant with level of depression ( $p$ $<0.05$ ).

After adjustment for covariates, female patients were more likely to suffer from severe anxiety and depression (OR $=4.536,95 \% \mathrm{Cl}: 1.806-11.395),(\mathrm{OR}=$ $3.160,95 \% 1.716-5.820) \quad(p<0.01)$ respectively. Depressive patients had a higher risk of anxiety (OR $=1.430,95 \% \mathrm{Cl}: 1.214-1.685)$ ( $p=0.000)$. Similarly, anxious patients were more prone to be depressive $(\mathrm{OR}=1.605,95 \% \mathrm{Cl}: 1.354-1.903)(\mathrm{p}=0.000) . \mathrm{BMI}$ and alcohol use were significantly associated with an increased risk of depression $(O R=1.747,95 \% \mathrm{Cl}$ : 1.021-2.899) $(\mathrm{OR}=1.939,95 \% \mathrm{Cl}: 1.090-3.450)$. Number of Comorbidities and Marital status were also found to be significantly linked to the severe depression (Table 2).

\section{Discussion}

COPD is a chronic and progressive disease which is usually caused by smoking which begins in adolescence age group and takes 20-25 years of exposure to induce characteristic pathophysiological changes in lungs of human beings. It takes several years to develop and it affects mostly older adults and however middle age people can also be affected because of their lifestyle.

Another important factor is domestic exposure of indoor pollution, resulting from burning solid biomass, other health-adverse fuels and usage of mosquito coil has emerged as another important risk factor for COPD. It has been observed that the exposure begins during early infancy and childhood, thus young adults were more susceptible for development of COPD at an early age. In humans, the lung function keeps improving until early adulthood and subsequently undergoes a natural physiological decline.

Therefore, we wish to estimate the demographic profile, level of anxiety and depression in COPD patients. It has been observed in this study that the overall mean \pm SD age of all patients was $49.17 \pm 8.29$ (25-62) years. Similarly Kristen E. Holm, et al observed that the mean baseline age of COPD was 60 years and the age range varies from (32-84) in his study (26) Another author MizuhaHaraguchi et al observed that the mean age of patient in his study was $72.6 \pm 8.2$, however the range was between 4391 years.(27)

COPD is rapidly becoming a global public health problem with smoking being recognized as its most important causative factor, various studies have shown that the combination of smoking and heavy drinking makes COPD worse.

In this study patients smoking rate among COPD patient was less $28.4 \%$ as compared to study 
conducted by Lundback et (28) al in which it was more i.e $50 \%$. It has been observed that $58.2 \%$ males and $41.8 \%$ females had a history of smoking however similar study conducted by Karadogan (29) observed that $50 \%$ males and $33.3 \%$ females had history of smoking (dilek), while the general recent smoking prevalence among individuals older than 40 years in Turkey (30) was approximately $40 \%$ among men and $13 \%$ among women.

It has been observed that majority (77.2\%) of the male respondents had a history of alcohol in this study, Contrary to our findings Kaluza J et al (31) observed that Moderate alcohol consumption was associated with the lowest risk of COPD, suggesting that moderate beer and wine consumption, but not liquor consumption, may decrease risk of COPD.

Dyspnea is one of the leading symptoms and sometimes the only one affecting patient suffering from COPD. Functional dyspnea has been shown to be a strong predictor of survival and an important treatable symptom of the disease. $(32,33)$

In our study the mean of MMRC Score was 3.16 \pm 1.28 similar to this TaghreedS et al (34) observed that in his study MMRC score was $3.26 \pm 0.74$.

In our study it has been observed that severity of dyspnea was almost equal in males and females. Similarly study by GuohuaJia observed that women rated MMRC dyspnea score was similar to men $(1.74 \pm 1.10$ vs $1.70 \pm 1.11, p \leq 0.05)$. (35) However, another author de Torres (36) observed that women with COPD reports more functional dysnpea for the same degree of airway obstruction.

Female patients reported a higher level of dyspnea than males for the same level of ventilatory impairment. Dyspnea was more strongly correlated with depression in women than in men. (37)

COPD is considered as a systemic disease with multiple co morbidities. Anxiety and depression are considered two of the most common and leasttreated comorbidities associated with it. A heightened experience of dyspnoea is likely to be a contributing factor to anxiety.

Average score of anxiety and depression were almost equal in our study and it was found to be statistically significant ( $p \leq 0.008, p \leq 0.005)$ however another author Amira $\mathrm{H}$ et al (38) observed that in COPD group, anxiety and depression were more prevalent in males with highly significant statistical differences for anxiety between males and females (p .004) and non-significant differences for depression.
In this study prevalence of anxiety was 18.77 and depression was 11.18 however in a study done by Amira H. et al (38) observed increased prevalence of anxiety and depression in COPD (22\%, 14\%).

The prognosis of chronic diseases in patients of chronic health conditions depends of treatment adherence which plays and important role in failure of treatments, increased risk for disease recurrence and its exacerbation, prolongation of treatment and increased health cost. (39)

In this study level of education, age and BMI were significantly associated with anxiety and depression similarly study by Negietal (40) observed that Lower educational status was associated with higher score of depression severity (beta $=-1.566, \mathrm{P}<0.01$ ). Higher $\mathrm{BMI}$ was associated with lower score of depression in patients with COPD (beta $=-0.779, P<0.01$ ), however no association was found with age and sex In our study females' patients have suffered more from anxiety (OR= 4.536, 95\% Cl :1.806-11.395), and depression (OR 3.16. $95 \% 1.716-5.820$ ), similarly study by Tian Xiao (41) also observe that after adjustment for covariates, female patients were more likely to suffer from anxiety $(\mathrm{aOR}=6.41,95 \%$ $\mathrm{Cl}$ : 1.73-23.80) and depression 1.48(0.69 3.19) in his study.

\section{Conclusion}

In conclusion, a substantial number of patients with COPD had both depression and anxiety and it is observed that depression was more common in unmarried females, patients with co morbidities and with high BMI. Therefore, detection of psychological co-morbidities should be emphasized in routine clinical practice in COPD patients.

\section{Recommendation}

It is recommended to conduct a stress management seminar at regular interval for COPD Patients.

\section{Limitation of the study}

The number of subjects enrolled in our study were less, we were not able to follow up the cases. It was a hospital-based study done in single hospital setting thus its results cannot be generalized for the community.

\section{Relevance of the study}

The study will be useful for policy makers, clinicians to plan the special clinics for COPD Patients on their felt needs. The strength of the study is that it is first of its kind being done in Dehradun, capital of Uttarakhand. 


\section{Authors Contribution}

All authors have contributed equally.

\section{Acknowledgement}

The authors acknowledge all the respondents involved in this study for their cooperation and support

\section{References}

1. World Health Organisation. Chronic obstructive pulmonary disease (COPD). 2017. Available from https://www.who.int/news-room/fact-sheets/detail/chronicobstructive-pulmonary-disease-(copd) . [Last Accessed on 20 feb, 2021]

2. Global Initiative for Chronic Obstructive Lung Disease - GOLD Guideline: Global Strategy for the Diagnosis, Treatment, and Prevention of Chronic Obstructive Pulmonary Disease. 2011. Available from: http://www.goldcopd.com . [Last Accessed on 20 Feb 2021]

3. GBD 2015 Chronic Respiratory Disease Collaborators. Global, regional, and national deaths, prevalence, disability-adjusted life years, and years lived with disability for chronic obstructive pulmonary disease and asthma, 1990-2015: a systematic analysis for the Global Burden of Disease Study 2015. The Lancet. Respiratory Medicine. 2017;5(9):691-706.

4. India State-Level Disease Burden Initiative Collaborators. Nations within a nation: variations in epidemiological transition across the states of India, 1990-2016 in the Global Burden of Disease Study. Lancet. 2017;390(10111):2437-2460. doi: 10.1016/S0140-6736(17)32804-0. Epub 2017 Nov 14. Erratum in: Lancet. 2017 Dec 2;390(10111):e49. PMID: 29150201; PMCID: PMC5720596.[PubMed].

5. ICMR, PHFI, IHME. India: Health of the Nation's States - The India state-level disease burden initiative. New Delhi: Indian Council of Medical Research, Public Health Foundation of India, Institute for Health metrics and Evaluation, 2017.

6. Global, regional, and national deaths, prevalence, disabilityadjusted life years, and years lived with disability for chronic obstructive pulmonary disease and asthma, 1990-2015: a systematic analysis for the Global Burden of Disease Study 2015. Lancet Respir Med. 2017;5(9):691- 706. Available from: https://doi.org/10.1016/S2213-2600(17)30293-X

7. Cruz AA. Global surveillance, prevention and control of chronic respiratory diseases: a comprehensive approach. World Health Organization; 2007. Available from: https://www.who.int/gard/publications/GARD Manual/en/ [last access on 16 mar 2021]

8. ICMR PI, PHFI I. India: health of the nation's states: the india state-level disease burden initiative. New Delhi, India. 2017.

9. Mathers CD, Loncar D. Projections of global mortality and burden of disease from 2002 to 2030. PLoS Med. 2006;3(11):e442. doi: 10.1371/journal.pmed.0030442. PMID: 17132052; PMCID: PMC1664601.[PubMed].

10. Yohannes AM. Palliative care provision for patients with chronic obstructive pulmonary disease. Health Qual Life Outcomes. 2007;5:17. doi: 10.1186/1477-7525-5-17. PMID: 17407591; PMCID: PMC1852092.[PubMed].

11. Ng TP, Niti M, Tan WC, Cao Z, Ong KC, Eng P. Depressive symptoms and chronic obstructive pulmonary disease: effect on mortality, hospital readmission, symptom burden, functional status, and quality of life. Arch Intern Med. 2007;167(1):60-7. doi: 10.1001/archinte.167.1.60. PMID: 17210879. [PubMed].
12. Peveler R, Carson A, Rodin G. Depression in medical patients. BMJ. 2002;325(7356):149-52. doi: 10.1136/bmj.325.7356.149. PMID: 12130614; PMCID: PMC1123674.[PubMed].

13. Bentsen SB, Miaskowski C, Rustøen T. Demographic and clinical characteristics associated with quality of life in patients with chronic obstructive pulmonary disease. Qual Life Res. 2014;23(3):991-8. doi: 10.1007/s11136-013-0515-5. Epub 2013 Sep 3. PMID: 23999743. [PubMed].

14. Di Marco F, Verga $M$, Reggente $M$, Maria Casanova F, Santus $P$, Blasi F, Allegra L, Centanni S. Anxiety and depression in COPD patients: The roles of gender and disease severity. Respir Med. 2006;100(10):1767-74. doi: 10.1016/j.rmed.2006.01.026. Epub 2006 Mar 13. PMID: 16531031.[PubMed]

15. Eckerblad J, Tödt K, Jakobsson $P$, Unosson $M$, Skargren $E$, Kentsson $M$, Theander K. Symptom burden in stable COPD patients with moderate or severe airflow limitation. Heart \& Lung. 2014;43(4):351-7.

16. Kunik ME, Roundy K, Veazey C, Souchek J, Richardson P, Wray NP, Stanley MA. Surprisingly high prevalence of anxiety and depression in chronic breathing disorders. Chest. 2005;127(4):1205-11. doi: 10.1378/chest.127.4.1205. PMID: 15821196.[PubMed].

17. Reinke LF, Slatore CG, Udris EM, Moss BR, Johnson EA, Au DH. The association of depression and preferences for lifesustaining treatments in veterans with chronic obstructive pulmonary disease. J Pain Symptom Manage. 2011;41(2):40211. doi: 10.1016/j.jpainsymman.2010.05.012. Epub 2010 Dec 8. PMID: 21145201.[PubMed]

18. Walke LM, Byers AL, Tinetti ME, Dubin JA, McCorkle R, Fried TR. Range and severity of symptoms over time among older adults with chronic obstructive pulmonary disease and heart failure. Arch Intern Med. 2007;167(22):2503-8. doi: 10.1001/archinte.167.22.2503. PMID: 18071174; PMCID: PMC2196402.[PubMed].

19. Gore JM, Brophy CJ, Greenstone MA. How well do we care for patients with end stage chronic obstructive pulmonary disease (COPD)? A comparison of palliative care and quality of life in COPD and lung cancer. Thorax. 2000;55(12):1000-6. doi: 10.1136/thorax.55.12.1000. PMID: 11083884; PMCID: PMC1745647.[PubMed].

20. Wagena EJ, Arrindell WA, Wouters EF, van Schayck CP. Are patients with COPD psychologically distressed? Eur Respir J. 2005;26(2):242-8. doi: 10.1183/09031936.05.00010604. PMID: 16055871.[PubMed].

21. McCathie HC, Spence SH, Tate RL. Adjustment to chronic obstructive pulmonary disease: the importance of psychological factors. Eur Respir J. 2002;19(1):47-53. doi: 10.1183/09031936.02.00240702. PMID: 11852894.[PubMed].

22. Atlantis E, Fahey P, Cochrane B, Smith S. Bidirectional associations between clinically relevant depression or anxiety and COPD: a systematic review and meta-analysis. Chest. 2013;144(3):766-777. doi: 10.1378/chest.12-1911. PMID: 23429910. [PubMed].

23. Zigmond AS, Snaith RP. The hospital anxiety and depression scale. Acta Psychiatr Scand. 1983;67(6):361-70. doi: 10.1111/j.1600-0447.1983.tb09716.x. PMID: 6880820.[PubMed]

24. Mahler DA, Wells CK. Evaluation of clinical methods for rating dyspnea. Chest. 1988;93(3):580-6. doi: 10.1378/chest.93.3.580. PMID: 3342669.[PubMed]

25. Vural B, Acar ÖT, Topsever P, Filiz TM. Reliability and validity of Turkish version of modified Morisky scale. The Journal of Turkish Family Physician. 2012:17-20

26. Holm KE, Plaufcan MR, Ford DW, Sandhaus RA, Strand M, Strange C, Wamboldt FS. The impact of age on outcomes in chronic obstructive pulmonary disease differs by relationship 
status. J Behav Med. 2014;37(4):654-63. doi: 10.1007/s10865013-9516-7. Epub 2013 May 4. PMID: 23645147; PMCID: PMC3772963. [PubMed].

27. Haraguchi M, Nakamura H, Sasaki M, Miyazaki M, Chubachi S, Takahashi S, Asano K, Jones PW, Betsuyaku T; Keio COPD Comorbidity Research (K-CCR) Group. Determinants of chronic obstructive pulmonary disease severity in the late- elderly differ from those in younger patients. BMC Res Notes. 2016 ;9:7. doi: 10.1186/s13104-015-1810-8. PMID: 26728686; PMCID: PMC4700610.[PubMed].

28. Lundbäck $B$, Lindberg $A$, Lindström $M$, Rönmark $E$, Jonsson $A C$, Jönsson E, Larsson LG, Andersson S, Sandström T, Larsson K; Obstructive Lung Disease in Northern Sweden Studies. Not 15 but $50 \%$ of smokers develop COPD?--Report from the Obstructive Lung Disease in Northern Sweden Studies. Respir Med. 2003;97(2):115-22. doi: 10.1053/rmed.2003.1446. PMID: 12587960.[PubMed]

29. Karadogan D, Onal O, Sahin DS, Kanbay Y. Factors associated with current smoking in COPD patients:A cross-sectional study from the Eastern Black Sea region of Turkey. Tob Induc Dis. 2018;16:22. doi: 10.18332/tid/90665. PMID: 31516422; PMCID: PMC6659549.[PubMed].

30. Public Health Institution of Turkey. Global Adult Tobacco Survey 2012. 2014; 1-248. Available from http://www.who.int/tobacco/surveillance/survey/gats/report tur 2012.pdf?ua=1 [Last Accessed on Feb 26, 2021].

31. Kaluza J, Harris HR, Linden A, Wolk A. Alcohol Consumption and Risk of Chronic Obstructive Pulmonary Disease: A Prospective Cohort Study of Men. Am J Epidemiol. 2019;188(5):907-916. doi: 10.1093/aje/kwz020. PMID: 30877760.[PubMed].

32. Celli BR, Cote CG, Marin JM, Casanova C, Montes de Oca M, Mendez RA, Pinto Plata V, Cabral HJ. The body-mass index, airflow obstruction, dyspnea, and exercise capacity index in chronic obstructive pulmonary disease. N Engl J Med. 2004;350(10):1005-12. doi: 10.1056/NEJMoa021322. PMID: 14999112.[PubMed].

33. Nishimura K, Izumi T, Tsukino M, Oga T. Dyspnea is a better predictor of 5-year survival than airway obstruction in patients with COPD. Chest. 2002;121(5):1434-40. doi: 10.1378/chest.121.5.1434. PMID: 12006425.[PubMed]
34. Farag TS, Sobh ES, Elsawy SB, Fahmy BM. Evaluation of healthrelated quality of life in patients with chronic obstructive pulmonary disease. Egyptian Journal of Bronchology. 2018;12(3):288-94.

35. Jia G, Lu M, Wu R, Chen Y, Yao W. Gender difference on the knowledge, attitude, and practice of COPD diagnosis and treatment: a national, multicenter, cross-sectional survey in China. Int J Chron Obstruct Pulmon Dis. 2018;13:3269-3280. doi: 10.2147/COPD.S176173. PMID: 30349232; PMCID: PMC6188108. [PubMed].

36. de Torres JP, Casanova C, Hernández C, Abreu J, Aguirre-Jaime $A$, Celli BR. Gender and COPD in patients attending a pulmonary clinic. Chest. 2005;128(4):2012-6. doi: 10.1378/chest.128.4.2012. PMID: 16236849.[PubMed]

37. Di Marco F, Verga $M$, Reggente $M$, Maria Casanova F, Santus $P$, Blasi F, Allegra L, Centanni S. Anxiety and depression in COPD patients: The roles of gender and disease severity. Respir Med. 2006;100(10):1767-74. doi: 10.1016/j.rmed.2006.01.026. Epub 2006 Mar 13. PMID: 16531031.[PubMed]

38. Allam AH, Rawy AM, Abdeldayem OM, Mogahed MM, Abdelazeem E. Prevalence of anxiety and depression in patients with airway obstruction using hospital anxiety and depression scale (HADS) in different localities of Saudi Arabia. Egyptian Journal of Chest Diseases and Tuberculosis. 2017;66(4):617-22.

39. Turan O, Emre JC, Deniz S, Baysak A, Turan PA, Mirici A. Adherence to Current COPD Guidelines in Turkey. Expert Opin Pharmacother. 2016;17(2):153-8. doi: 10.1517/14656566.2016.1115482. Epub 2015 Dec 2. PMID: 26629809.[PubMed].

40. Negi H, Sarkar M, Raval AD, Pandey K, Das P. Presence of depression and its risk factors in patients with chronic obstructive pulmonary disease. Indian J Med Res. 2014;139(3):402-8. PMID: 24820834; PMCID: PMC4069734. [PubMed].

41. Xiao T, Qiu H, Chen Y, Zhou X, Wu K, Ruan X, Wang N, Fu C. Prevalence of anxiety and depression symptoms and their associated factors in mild COPD patients from community settings, Shanghai, China: a cross-sectional study. BMC Psychiatry. 2018;18(1):89. doi: 10.1186/s12888-018-1671-5. PMID: 29614998; PMCID: PMC5883260.[PubMed]

\section{Tables}

TABLE 1 CHARACTERISTICS OF COPD PATIENTS ACCORDING TO ANXIETY OR DEPRESSION STATUS

\begin{tabular}{|c|c|c|c|c|c|c|c|c|}
\hline \multirow[t]{2}{*}{ Characteristics } & \multicolumn{3}{|c|}{ Anxiety } & \multirow[t]{2}{*}{$p$-value } & \multicolumn{3}{|c|}{ Depression } & \multirow[t]{2}{*}{$\begin{array}{c}\mathrm{P}- \\
\text { value }\end{array}$} \\
\hline & Minimal & Mild & Moderate & & Minimal & Mild & Moderate & \\
\hline Age & $51.46 \pm 5.24$ & $50.91 \pm 7.57$ & $48.63 \pm 8.57$ & 0.238 & $49.32 \pm 7.67$ & $51.35 \pm 6.55$ & $47.8 \pm 19.27$ & 0.048 \\
\hline \multicolumn{9}{|l|}{ Gender } \\
\hline Male & $10(8.1)$ & $27(21.8)$ & $87(70.2)$ & \multirow[b]{2}{*}{0.003} & $39(31.5)$ & $40(32.3)$ & $45(36.3)$ & \multirow[t]{2}{*}{0.001} \\
\hline Female & $1(1.4)$ & $5(7.1)$ & $64(91.4)$ & & $13(18.6)$ & $12(17.1)$ & $45(64.3)$ & \\
\hline \multicolumn{9}{|l|}{ Occupation } \\
\hline Skilled & $9(5.8)$ & $26(16.9)$ & 119(77.3) & \multirow[t]{2}{*}{0.933} & $43(27.9)$ & $39(25.3)$ & $72(46.8)$ & \multirow[t]{2}{*}{0.613} \\
\hline Unskilled & $2(5.0)$ & $6(15.0)$ & $32(80.0)$ & & $9(22.5)$ & $13(32.5)$ & $18(45.0)$ & \\
\hline \multicolumn{9}{|l|}{ Marital Status } \\
\hline Married & $11(6.6)$ & $27(16.3)$ & $128(77.1)$ & \multirow[t]{2}{*}{0.373} & $51(30.7)$ & $44(26.5)$ & $71(42.8)$ & \multirow[t]{2}{*}{0.007} \\
\hline Unmarried & $0(0.0)$ & $5(17.9)$ & $23(82.1)$ & & $1(3.6)$ & $8(28.6)$ & 19(67.9) & \\
\hline \multicolumn{9}{|l|}{ Education Status } \\
\hline No schooling & $8(16.3)$ & $7(14.3)$ & $34(69.4)$ & \multirow{3}{*}{0.002} & $15(30.6)$ & $0(0.0)$ & $34(69.4)$ & \multirow[t]{3}{*}{0.000} \\
\hline Primary & $0(0.0)$ & $0(0.0)$ & $32(100.0)$ & & $17(53.1)$ & $5(15.6)$ & $10(31.3)$ & \\
\hline Secondary & $1(3.2)$ & $5(16.1)$ & $25(80.6)$ & & $12(38.7)$ & $11(35.5)$ & $8(25.8)$ & \\
\hline
\end{tabular}


INDIAN JOURNAL OF COMMUNITY HEALTH / VOL 33 / ISSUE NO 01 / JAN- MAR 2021

[Depression and Anxiety...] | SinhaR et al

\begin{tabular}{|c|c|c|c|c|c|c|c|c|}
\hline \multirow{3}{*}{ High school } & \multirow{2}{*}{$1(1.9)$} & \multirow{3}{*}{$\begin{array}{l}13(24.1) \\
7(25.0)\end{array}$} & \multirow{3}{*}{$\begin{array}{l}40(74.1) \\
20(71.4)\end{array}$} & & \multirow{3}{*}{$\begin{array}{l}7(13.0) \\
1(3.6)\end{array}$} & \multirow{3}{*}{$\begin{array}{l}18(33.3) \\
18(64.3)\end{array}$} & \multirow{3}{*}{$\begin{array}{l}29(53.7) \\
9(32.1)\end{array}$} & \\
\hline & & & & & & & & \\
\hline & $1(3.6)$ & & & & & & & \\
\hline \multicolumn{9}{|c|}{ Number of Comorbidities } \\
\hline 0 & $7(6.2)$ & $21(18.6)$ & $85(75.2)$ & \multirow{4}{*}{0.654} & $35(31.0)$ & $28(24.8)$ & $50(44.2)$ & \multirow[b]{4}{*}{0.044} \\
\hline 1 & $2(4.3)$ & $9(19.6)$ & $35(76.1)$ & & $13(28.3)$ & $17(37.0)$ & $16(34.8)$ & \\
\hline 2 & $2(6.3)$ & $2(6.3)$ & $28(87.5)$ & & $4(12.5)$ & $7(21.9)$ & $21(65.6)$ & \\
\hline 3 & $0(0.0)$ & $0(0.0$ & $3(100.0)$ & & $0(0.0)$ & $0(0.0)$ & $3(100.0)$ & \\
\hline \multicolumn{9}{|l|}{ Smoking } \\
\hline Yes & $3(5.5)$ & $12(21.8)$ & $40(72.7)$ & \multirow[t]{2}{*}{0.453} & $13(23.6)$ & $15(27.3)$ & $27(49.1)$ & \multirow[b]{2}{*}{0.813} \\
\hline No & $8(5.8)$ & $20(14.4)$ & $111(79.9)$ & & $39(28.1)$ & $37(26.6)$ & $63(45.3)$ & \\
\hline \multicolumn{9}{|l|}{ Alcohol Use } \\
\hline Yes & $8(9.1)$ & $14(15.9)$ & $66(75.0)$ & \multirow[t]{2}{*}{0.172} & $33(37.5)$ & $22(25.0)$ & $33(37.5)$ & \multirow[t]{2}{*}{0.007} \\
\hline No & $3(2.8)$ & $18(17.0)$ & $85(80.2)$ & & 19(17.9) & $30(28.3)$ & $57(53.8)$ & \\
\hline \multicolumn{9}{|l|}{ Knowledge } \\
\hline Low & $2(2.8)$ & $10(14.1)$ & $59(83.1)$ & \multirow[t]{2}{*}{0.301} & $20(28.2)$ & $15(21.1)$ & $36(50.7)$ & \multirow[t]{2}{*}{0.392} \\
\hline High & $9(7.3)$ & $22(17.9)$ & $92(74.8)$ & & $32(26.0)$ & $37(30.1)$ & $54(43.9)$ & \\
\hline \multicolumn{9}{|l|}{ Motivation } \\
\hline Low & $2(3.1)$ & $7(10.9)$ & $55(85.9)$ & \multirow[t]{2}{*}{0.158} & $24(37.5)$ & $11(17.2)$ & $29(45.3)$ & \multirow[t]{2}{*}{0.025} \\
\hline High & $9(6.9)$ & $25(19.2)$ & $96(73.8)$ & & $28(21.5)$ & $41(31.5)$ & $61(46.9)$ & \\
\hline BMI & $20.32 \pm 3.65$ & $21.87 \pm 1.63$ & $18.76 \pm 1.90$ & 0.044 & $19.64 \pm 2.44$ & $20.98 \pm 2.38$ & $17.85 \pm 1.22$ & 0.001 \\
\hline Disease duration & $6.55 \pm 4.34$ & $5.19 \pm 3.62$ & $5.61 \pm 3.93$ & 0.607 & $6.60 \pm 3.91$ & $5.56 \pm 3.76$ & $5.03 \pm 3.89$ & 0.070 \\
\hline MMRC & $2.72 \pm 1.62$ & $3.12 \pm 1.29$ & $3.13 \pm 1.35$ & 0.621 & $2.80 \pm 1.33$ & $3.15 \pm 1.36$ & $3.26 \pm 1.29$ & 0.148 \\
\hline
\end{tabular}

TABLE 2 RISK OF ANXIOUS AND DEPRESSIVE SYMPTOMS IN PATIENTS WITH COPD

\begin{tabular}{|l|c|c|c|c|c|c|}
\hline & \multicolumn{2}{c}{ Anxiety (Mild, Moderate Vs Severe) } & \multicolumn{2}{c|}{ Depression(Mild, Moderate Vs Severe) } \\
\hline Age & Odds Ratio & $\mathbf{9 5 \%}$ (CI) & $\mathbf{p}$ & Odds Ratio & $\mathbf{9 5 \%}$ (CI) & $\mathbf{p}$ \\
\hline Female & 0.960 & $0.915-1.007$ & 0.096 & 0.963 & $0.930-0.998$ & $\mathbf{0 . 0 3 7}$ \\
\hline Education Level & 4.536 & $1.806-11.395$ & $\mathbf{0 . 0 0 1}$ & 3.160 & $1.716-5.820$ & $\mathbf{0 . 0 0 0}$ \\
\hline Unskilled Worker & 0.875 & $0.315-2.429$ & 0.798 & 0.408 & $0.157-1.063$ & 0.067 \\
\hline Unmarried & 1.176 & $0.497-2.784$ & 0.712 & 0.932 & $0.463-1.874$ & 0.843 \\
\hline Comorbidities & 1.366 & $0.486-3.835$ & 0.554 & 2.825 & $1.207-6.613$ & $\mathbf{0 . 0 1 7}$ \\
\hline Smoking & 1.446 & $0.908-2.302$ & 0.120 & 1.454 & $1.020-2.072$ & $\mathbf{0 . 0 3 9}$ \\
\hline Alcohol Use & 1.487 & $0.721-3.066$ & 0.283 & 0.860 & $0.460-1.607$ & 0.635 \\
\hline Duration of COPD & 1.349 & $0.684-2.660$ & 0.387 & 1.939 & $1.090-3.450$ & $\mathbf{0 . 0 2 4}$ \\
\hline Knowledge_High Level & 0.931 & $0.863-1.004$ & 0.065 & 1.005 & $0.921-1.097$ & 0.912 \\
\hline Motivation_High Level & 0.604 & $0.287-1.268$ & 0.183 & 0.761 & $0.424-1.367$ & 0.361 \\
\hline MMRC & 0.462 & $0.206-1.034$ & 0.060 & 1.067 & $0.585-1.946$ & 0.833 \\
\hline BMI & 1.064 & $0.825-1.373$ & 0.634 & 1.171 & $0.944-1.452$ & 0.151 \\
\hline Depression & 0.895 & $0.765-1.047$ & 0.165 & 1.747 & $1.021-2.899$ & $\mathbf{0 . 0 0 2}$ \\
\hline Anxiety & 1.430 & $1.214-1.685$ & $\mathbf{0 . 0 0 0}$ & & & \\
\hline & & & & 1.605 & $1.354-1.903$ & $\mathbf{0 . 0 0 0}$ \\
\hline
\end{tabular}

